\title{
Restoring expression of wild-type p53 suppresses tumor growth but does not cause tumor regression in mice with a $p 53$ missense mutation
}

\author{
Yongxing Wang, ${ }^{1,2}$ Young-Ah Suh, ${ }^{1}$ Maren Y. Fuller, ${ }^{1,2}$ James G. Jackson, ${ }^{1}$ \\ Shunbin Xiong, ${ }^{1}$ Tamara Terzian, ${ }^{1}$ Alfonso Quintás-Cardama, ${ }^{3}$ \\ James A. Bankson, ${ }^{4}$ Adel K. El-Naggar, ${ }^{5}$ and Guillermina Lozano, ${ }^{1,2}$

\begin{abstract}
1Department of Genetics, The University of Texas MD Anderson Cancer Center, Houston, Texas, USA. 2Program in Genes and Development, Graduate School of Biomedical Sciences, The University of Texas Health Science Center, Houston, Texas, USA. ${ }^{3}$ Department of Leukemia, ${ }^{4}$ Department of Imaging Physics, and ${ }^{5}$ Department of Pathology, The University of Texas MD Anderson Cancer Center, Houston, Texas, USA.
\end{abstract}

\begin{abstract}
The transcription factor p53 is a tumor suppressor. As such, the P53 gene is frequently altered in human cancers. However, over $80 \%$ of the P53 mutations found in human cancers are missense mutations that lead to expression of mutant proteins that not only lack p53 transcriptional activity but exhibit new functions as well. Recent studies show that restoration of p53 expression leads to tumor regression in mice carrying $p 53$ deletions. However, the therapeutic efficacy of restoring p53 expression in tumors containing $p 53$ missense mutations has not been evaluated. Here we demonstrate that restoring wild-type p53 expression halted tumor growth in mice inheriting a $p 53^{R 172 H}$ missense mutation that is equivalent to a $P 53$ missense mutation detected in approximately $6 \%$ of human cancers. However, it did not lead to tumor regression, as was observed in mice lacking $p 53$. We further showed that the dominant-negative effect of the mutant $\mathrm{p} 53$ encoded by $p 53^{R 172 H}$ dampened the activity of the restored wild-type p53. We therefore conclude that in a mutant p53 background, p53 restoration has the therapeutic potential to suppress tumor progression. Our findings support using p53 restoration as a strategy to treat human cancers with P53 missense mutations and provide direction for optimizing $\mathrm{p} 53$ restoration in cancer therapy.
\end{abstract}

\section{Introduction}

The tumor suppressor p53 is a transcription factor. Upon activation by signals, such as DNA damage, oncogenic stimuli, and hypoxia, wild-type p53 activates the transcription of genes involved in apoptosis, cell cycle arrest, differentiation, and senescence $(1,2)$. These potent antitumor activities prevent cells with aberrant growth signals from proliferating. Approximately, half of human cancers have $P 53$ gene alterations that result in loss of p53 activity. While a few of these alterations are P53-null mutations, over $80 \%$ are $P 53$ missense mutations that lead to expression of mutant p 53 proteins $(3,4)$. Many p53 missense mutants lack p53 transcriptional activity and show gain-of-function activities.

In particular, the arginine-to-histidine mutation at codon 175 of the P53 gene (corresponding to $p 53^{R 172 H}$ in mice) occurs in about $6 \%$ of human cancers (5). The $p 53^{R 172 H}$ mutation has gain-of-function properties, manifested as a tumor metastasis phenotype in $p 53^{R 172 H}$ heterozygous mice that is lacking in $p 53^{+/-}$mice $(6,7)$. Another property of the $\mathrm{p} 53 \mathrm{R} 172 \mathrm{H}$ mutant is its dominant-negative effect that silences wild-type p53 under some circumstances (8). Thus, for example, in response to $\gamma$-irradiation, mutant p53R172H inactivates wild-type p53 activities (9). Additionally, mutant p53 binds and suppresses the activities of the related proteins, $\mathrm{p} 63$ and $\mathrm{p} 73$ (7). However, the $p 53^{R 172 H}$ heterozygous mice that express equal amounts of wild-type and mutant p53 have survival curves identical to those of $p 53^{+/-}$mice, indicating that

Conflict of interest: The authors have declared that no conflict of interest exists. Citation for this article: J Clin Invest. 2011;121(3):893-904. doi:10.1172/JCI44504. mutant p53 does not inactivate wild-type p53 (8). One possible explanation for this discrepancy is that once stabilized, mutant p53 has a longer half-life than wild-type p53 and thus overwhelms wild-type p53 function (10).

Since p53 inactivation is common in human cancers, p53 restoration offers a very promising therapy for cancer treatment. The replenished wild-type $\mathrm{p} 53$, if properly activated, confers cell cycle arrest and cell death, both of which represent effective mechanisms of tumor suppression (11). Recent mouse tumor studies have provided direct evidence to support the rationale for using p53 restoration in cancer therapy. Three research groups independently generated genetically modified mice that allowed restoration of wild-type p53 expression in tumors lacking p53 (12-14). The lymphomas, sarcomas, and carcinomas that developed in these mice regressed after $\mathrm{p} 53$ restoration by initiating apoptosis or senescence in a tumor-specific manner. While exciting, these studies do not address the effects of p53 restoration in tumors with mutant p53, as would be the case in many human tumors. The activity of the restored wild-type p53 might be compromised by the stabilized mutant p53 in tumors. We hypothesized that in a mutant p53 background, the restored wild-type p53 may be less effective as a tumor suppressor.

The purpose of this study was to evaluate the therapeutic efficacy of $\mathrm{p} 53$ restoration in spontaneous mouse tumors with mutant p53. We generated a mouse model that allowed wildtype $\mathrm{p} 53$ restoration in vivo and demonstrated that $\mathrm{p} 53$ restoration led to tumor regression in mice lacking p53, as previously published (13). More importantly, p53 restoration halted tumor 


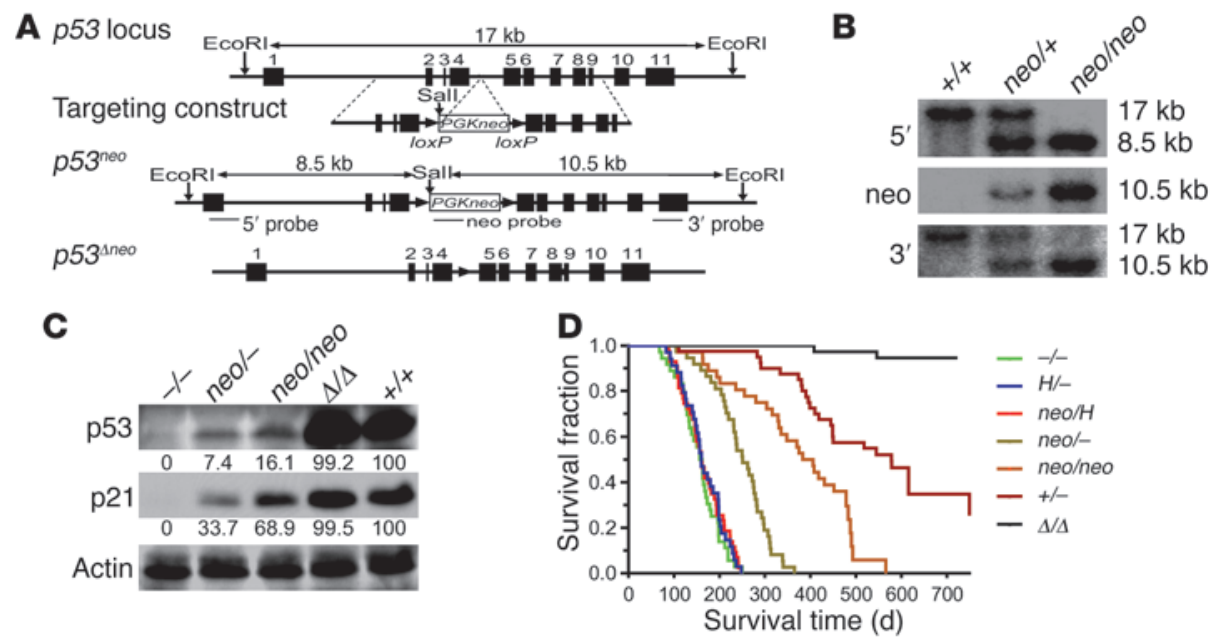

Figure 1

Generation of a latent $p 53^{\text {neo }}$ allele. (A) Targeting strategy to generate $p 53^{\text {neo }}$ and $p 53^{\Delta n e o}$ alleles. The $p 53^{\text {neo }}$ allele, with insertion of the $P G K n e o$ gene flanked by loxP sites (triangles) in intron 4 (introns are represented by lines and exons by rectangles), was generated by homologous recombination. The $p 53^{\Delta n e o}$ allele was generated by crossing $p 53^{\text {neo/+ }}$ mice with ZP3-Cre transgenic mice. (B) Southern blot analysis of tail DNA

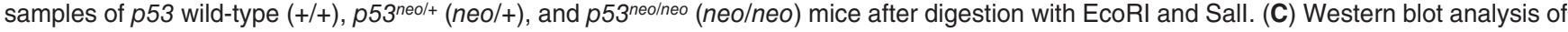

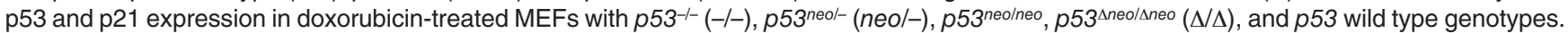
Levels of p53 and p21 were normalized to actin. The numbers under lanes indicate the p53 and p21 protein levels (percentages) relative to those for wild-type mice. (D) Survival curves of $p 53^{-/-}(n=35), p 53^{R 172 H /-}(H /-, n=34), p 53^{\text {neo/R172H }}(n e o / H, n=40), p 53^{\text {neo/- }}(n=37)$, $p 53^{\text {neo/neo }}(n=30)$, $p 53^{+/-}(+/-, n=40)$, and $p 53^{\text {Aneo/Aneo }}(n=38)$ mice.

growth in mice containing the $p 53^{R 172 H}$ mutation, although it did not lead to tumor regression. We further showed that the dominant-negative effect of the p53R172H mutant dampened the activity of the restored wild-type p53. Our results support the use of 553 restoration in the treatment of human cancers with p53 missense mutations.

\section{Results}

Generation of a latent $p 53$ allele. We generated a latent $p 53$ allele using gene targeting. This allele, designated the $p 53^{\text {neo }}$ allele, contained a floxed PGKneo cassette that was inserted into intron 4 of the $p 53$ locus (Figure 1A). $p 53$ was confirmed to be wild type by sequencing (data not shown). Southern blot analysis was used to verify correct targeting and germline transmission of the $p 53^{\text {neo }}$ allele in mice (Figure 1B). The PGKneo cassette was removed from the $p 53^{\text {neo }}$ allele by Cre recombination, and the resultant allele was designated $p 53^{\Delta \text { neo }}$ (Figure $\left.1 \mathrm{~A}\right)$. The $\mathrm{p} 53$ expression from the $p 53^{\text {neo }}$ and $p 53^{\Delta \text { neo }}$ alleles was examined in mouse embryonic fibroblasts (MEFs) (Figure 1C). After doxorubicin treatment, the levels of p53 expression in $p 53^{\text {neo/- }}$ and $p 53^{\text {neo/neo }}$ MEFs were $7.4 \%$ and $16.1 \%$, respectively, of the level of p53 expression in $p 53^{+/+}$MEFs (Figure 1C), while $p 53^{+/-}$MEFs were $50.5 \%$ of the level of $\mathrm{p} 53$ expression in $p 53^{+/+}$MEFs (Supplemental Figure 1; supplemental material available online with this article; doi:10.1172/JCI44504DS1). $p 53^{\text {neo- }}$ and $p 53^{\text {nеo/nеo }}$ MEFs activated $p 21$, a direct target of $\mathrm{p} 53$, at $33.7 \%$ and $68.9 \%$ that of $p 53^{+/+}$MEFs, respectively. Equivalent p53 and p21 protein levels were observed in $p 53^{\Delta \text { пno/ } \Delta \text { neo }}$ and $p 53^{+/+}$MEFs. Thus, the PGKneo cassette downmodulated endogenous p53 expression from the $p 53^{\text {neo }}$ allele, and deletion of $P G K n e o$ allowed restoration of normal p53 levels.

Transformed mouse $3 \mathrm{~T} 3$ cell double minute $2(\mathrm{Mdm} 2)$ is a potent p53 inhibitor, and the embryonic lethality of $M d m 2$-null mice is rescued by concomitant deletion of $p 53(15,16)$. Thus, the
Mdm2-null phenotype offers a unique opportunity to examine p53 activity in vivo. To examine whether the $p 53^{\text {neo }}$ allele was functionally null, we crossed $p 53^{-/-} M d m 2^{-/-}$mice with $p 53^{\text {neo/neo }} M d m 2^{+/-}$mice. Although $p 53^{\text {neo } /-} M d m 2^{-/-}$and $p 53^{\text {neo } /-} M d m 2^{+/-}$mice were born at the correct ratios, the $p 53^{\text {neo/- }} M d m 2^{-/-}$mice were smaller and less mobile than their $p 53^{\text {neo } /-} M d m 2^{+/-}$siblings and died by weaning age (Supplemental Figure 2 and Supplemental Table 1). The $p 53^{\text {neo/neo }}$ genotype did not rescue the embryonic lethality of $M d m 2^{-1-}$ mice (data not shown). Taken together, these data argue that the $p 53^{\text {neo }}$ allele retained some wild-type activity and was thus hypomorphic.

Table 1

Tumor spectra of $p 53^{\text {neo/R172H }}, p 53^{\text {neo- }}$, and $p 53^{\text {neo/neo }}$ mice

\begin{tabular}{|c|c|c|c|}
\hline Tumor type & $\begin{array}{c}p 53^{\text {neo/R172H }} \\
(n=38)\end{array}$ & $\begin{array}{l}p 53^{\text {neo/ }} \\
(n=38)\end{array}$ & $\begin{array}{c}p 53^{\text {neo/neo }} \\
(n=28)\end{array}$ \\
\hline Lymphomas & $31(59.6 \%)$ & $15(34.1 \%)$ & $10(32.2 \%)$ \\
\hline T cell lymphomas & 18 & 3 & 1 \\
\hline Diffuse lymphomas & 5 & 4 & 1 \\
\hline Large-cell lymphoma & 1 & & \\
\hline Anaplastic lymphoma & & 1 & \\
\hline Lymphoma, lymph node & & 1 & \\
\hline Lymphomas NOS & 7 & 6 & 8 \\
\hline Sarcomas & $19(36.5 \%)$ & $27(61.4 \%)$ & $19(61.3 \%)$ \\
\hline Angiosarcomas & 10 & 16 & 12 \\
\hline Spindle-cell sarcomas & 3 & 5 & 3 \\
\hline Giant-cell sarcomas & 1 & 2 & \\
\hline Anaplastic sarcomas & & 2 & \\
\hline Sarcomas NOS & 5 & 2 & 4 \\
\hline Lipoma & & $1(2.3 \%)$ & \\
\hline Adenocarcinomas & $2(3.8 \%)$ & $1(2.3 \%)$ & $2(6.5 \%)$ \\
\hline Total number of tumors & 52 & 44 & 31 \\
\hline
\end{tabular}

NOS, not otherwise specified. 
A

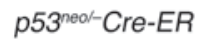
$p 53^{+/ 2}$

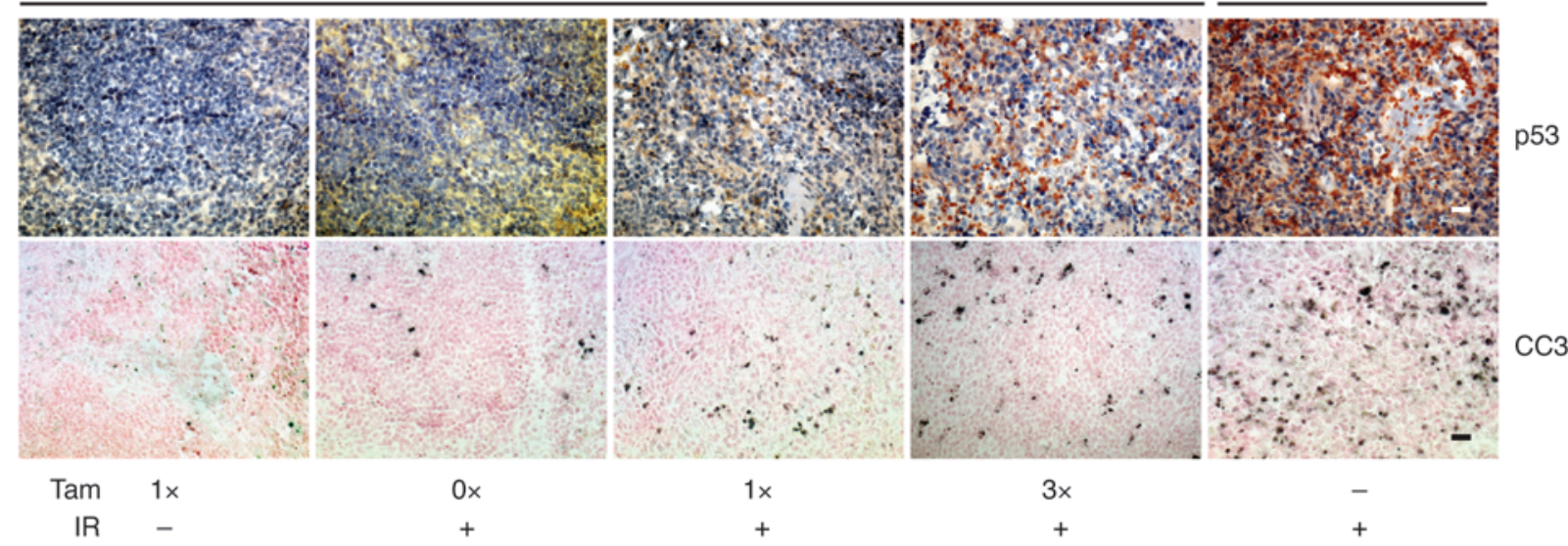

B

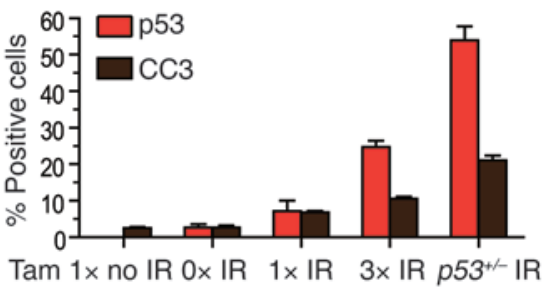

Figure 2

In vivo p53 restoration in a mouse model. (A) Immunohistochemistry of p53 and cleaved caspase-3 (CC3) in the spleens of vehicle- or tamoxifen-treated (Tam-treated) $p 53^{\text {neol- }}$ Cre-ERTM mice $(0 \times$, vehicle treatment; $1 \times$, tamoxifen treatment once; $3 \times$, tamoxifen treatment 3 times) exposed to 6 Gy $\gamma$-radiation (IR). Tissues were collected 5 hours after $\gamma$-radiation. The irradiated $p 53^{+/-}$mice were used as a positive control, and tamoxifen-treated $p 53^{\text {neol- }}$ Cre-ER $E R^{T M}$ mice without $\gamma$-radiation (no IR) were used as a negative control. Scale bar: $100 \mu \mathrm{m}$. (B) Percentages of cells staining positive for p53 and cleaved caspase-3 in A. Positive cells were counted in 4 random fields (original magnification, $\times 40$ ) and presented as the mean \pm SEM.

In crosses with $p 53^{R 172 H / R 172 H}$ mice, the $p 53^{\text {neo } / R 172 H} M d m 2^{-/-}$mice were completely rescued (Supplemental Figure 2 and Supplemental Table 1), indicating that the $p 53^{R 172 H}$ allele masked the wild-type activity of the $p 53^{\text {neo }}$ allele in vivo.

Analysis of survival and tumorigenesis. To monitor survival and tumor development, we generated cohorts of p53 mutant mice in the C57BL/ 6 background. Compared with $p 53^{-/-}$and $p 53^{+/-}$ mice with median survival time of 160 and 578 days, respectively, $p 53^{\text {neo/- }}$ and $p 53^{\text {neo/neo }}$ mice had median survival times of 251 and 395 days, respectively (Figure 1D). This gene-dosage effect on survival confirmed that the $p 53^{\text {neo }}$ allele was hypomorphic. In contrast, the survival curve of $p 53^{\text {neo } / R 172 H}$ mice was identical to those of $p 53^{-/-}$and $p 53^{R 172 H /-}$ mice (Figure 1D). Therefore, in $p 53^{\text {neo/R172H }}$ mice, the presence of $p 53^{R 172 H}$ eliminated the potential increase in survival allowed by the $p 53^{\text {neo }}$ allele. The $p 53^{\Delta \text { neo/ } \Delta \text { neo }}$ mice survived normally, with no tumor development by 25 months, similar to wild-type mice. Most $p 53^{\text {neo/- }}, p 53^{\text {neo/neo }}$, and $p 53^{\text {neo/R172H }}$ mice died of tumor development. The most common tumor types in these mice were lymphomas and sarcomas (Table 1). $p 53^{\text {neo/R172H }}$ mice developed $59.6 \%$ lymphomas and $36.5 \%$ sarcomas, which was similar to the $56 \%$ and $40 \%$ observed frequency, respectively, in $p 53^{-/-}$mice (7). In contrast, the $p 53^{\text {neo-- }}$ and $p 53^{\text {neo/neo }}$ mice showed an increased frequency of sarcomas $(61.4 \%$ and $61.3 \%$, respectively) with a decreased frequency of lymphoma development (34.1\% and 32.2\%, respectively), as compared with that in $p 53^{-1-}$ mice. Thus, expression of a small amount of wildtype p53 from the $p 53^{\text {neo }}$ allele led to a shift in tumor spectrum with an increase in the number of sarcomas, except in combination with the $p 53^{R 172 H}$ allele.

$p 53$ restoration in vivo. To temporally restore the $p 53$ gene in vivo, we generated $p 53^{\text {neo/- }} \mathrm{Cre}-E R^{T M}$ and $p 53^{\text {neo } / R 172 H} C r e-E R^{T M}$ mice. The Cre-ER $R^{T M}$ transgene constitutively expresses a Cre-ER fusion protein that becomes active only after tamoxifen exposure (17). Six-week-old $p 53^{\text {nеo- }-C r e-E R^{T M}}$ mice were treated with tamoxifen by weekly intraperitoneal injections. Southern blot analysis confirmed the conversion of the $p 53^{\text {neo }}$ allele to $p 53^{\Delta \text { neo }}$ in various tissues of mice treated for 1 or 3 weeks (Supplemental Figure 3). To determine how efficient $\mathrm{p} 53$ restoration was in activation of p53, we performed immunohistochemistry experiments with p53 and cleaved caspase- 3 antibodies after Cre-mediated recombination, followed by whole-body $\gamma$-irradiation (Figure 2). Increased p53 and cleaved caspase-3 staining were observed in the spleens and thymi of irradiated, tamoxifen-treated $p 53^{\text {neo } /-C r e-E R^{T M}}$ mice compared with that in mice of the same genotype without tamoxifen treatment. As a control, irradiated $p 53^{+/-}$mice showed extensive p53 activity (Figure 2 and Supplemental Figure 4). These data demonstrated that tamoxifen treatment worked effectively to trigger $\mathrm{p} 53$ restoration in vivo.

Tumor suppression after $p 53$ restoration. To characterize tumor response after $\mathrm{p} 53$ restoration, we established cohorts of $p 53^{\text {neo/ } R 172 H}$ and $p 53^{\text {neo/- }}$ mice with and without $C r e-E R^{T M}$. These mice underwent MRI periodically to screen for spontaneous tumor development. Upon detection of a tumor, mice were treated 4 times weekly with tamoxifen by intraperitoneal injection. If a mouse survived 

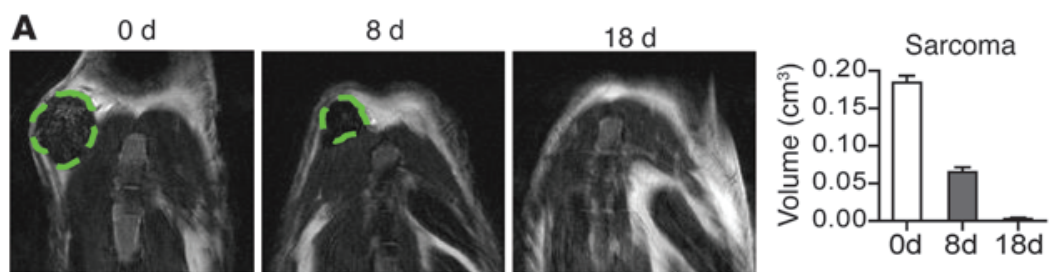

$0 \mathrm{~d}$

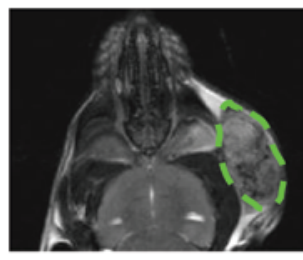

B
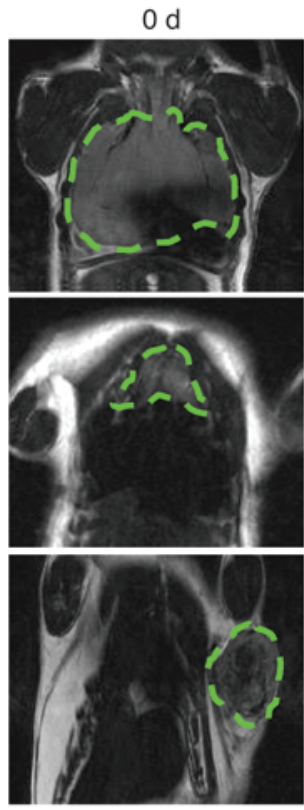

$0 \mathrm{~d}$

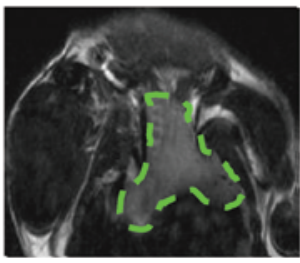

$0 d$

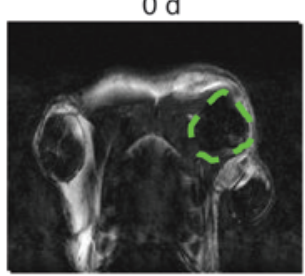

$14 \mathrm{~d}$

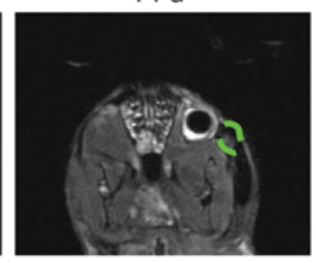

$28 d$
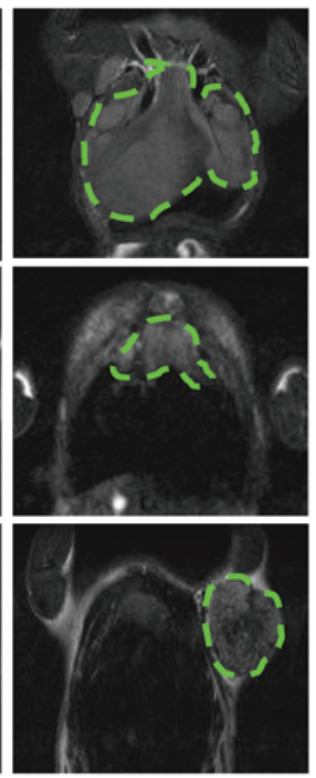

$8 d$

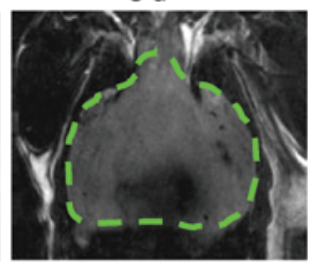

$14 \mathrm{~d}$

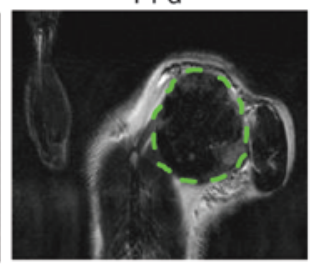

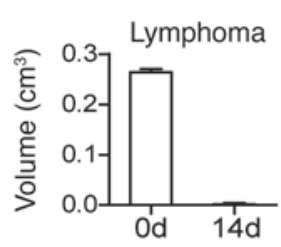
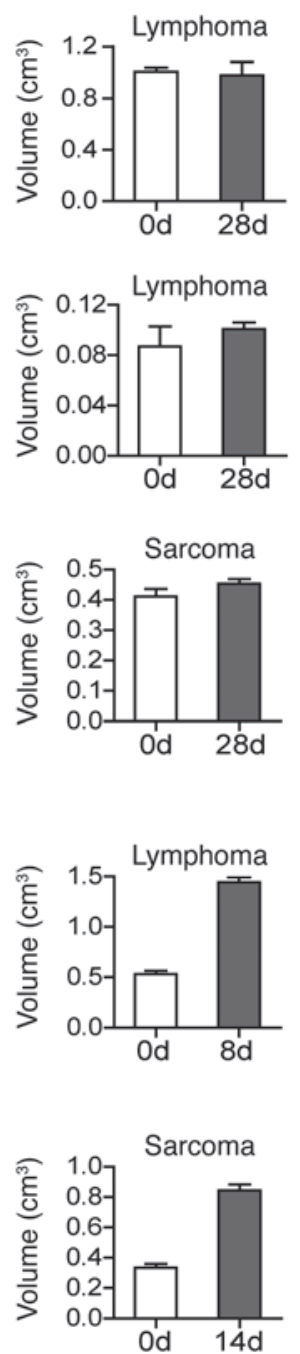

D

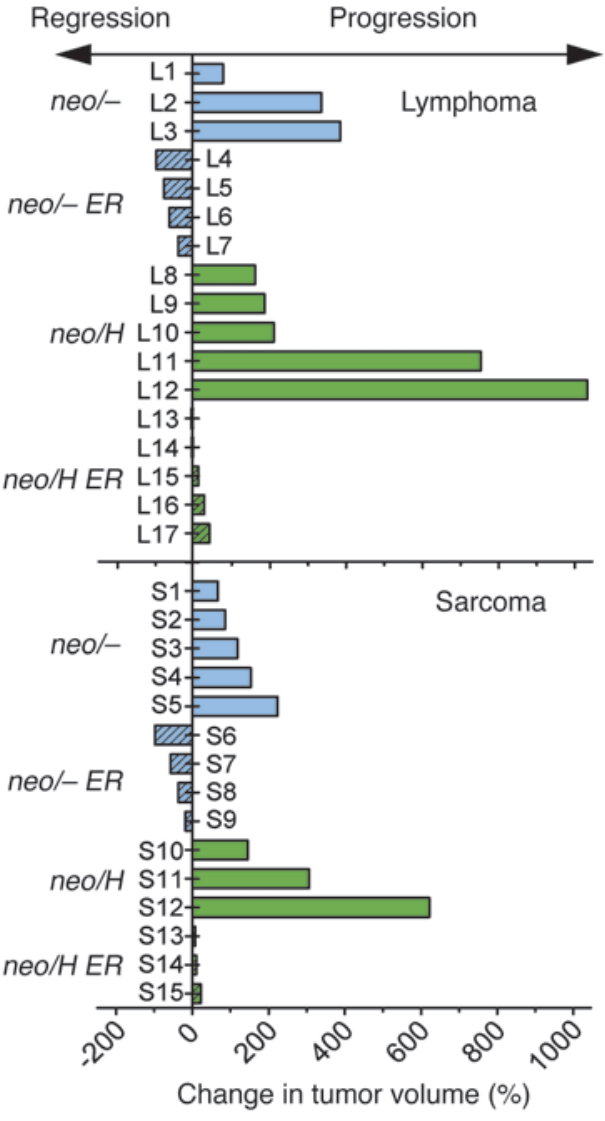

E

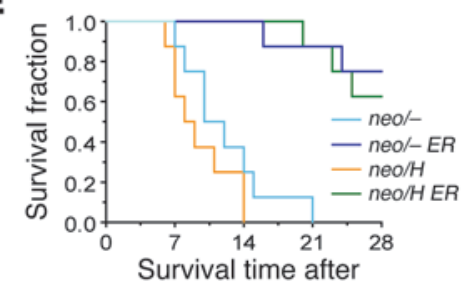

tamoxifen treatment (d) 


\section{Figure 3}

p53 restoration led to tumor regression in $p 53^{\text {neol- }}$ Cre- $E R^{T M}$ mice and suppressed tumor progression in $p 53^{\text {neo/R172H }} \mathrm{Cre}-E R^{T M}$ mice. (A) Tumor MRI images and tumor volume calculations in representative

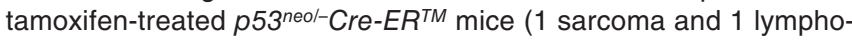
ma). (B) Tumor MRI images and tumor volume calculations in representative tamoxifen-treated $p 53^{n e o / R 172 H} C r e-E R^{T M}$ mice (2 lymphomas and 1 sarcoma). (C) Tumor MRI images and tumor volume calculations in representative tamoxifen-treated $p 53^{\text {neo/R172 }}$ mice (1 lymphoma and 1 sarcoma). (A-C) Tumor volume measurements were obtained in $\mathrm{cm}^{3}$ from T2-weighted MRI image stacks. For each time point, measurements $(n=4)$ from image sequences were used to calculate a mean volume \pm SEM. Day $0(0 \mathrm{~d})$ indicates the day before tamoxifen treatment; day $8,14,18$, and 28 indicate $8,14,18$, and 28 days after tamoxifen treatment, respectively. Green dashed lines outline representative tumor images (coronal view, no magnification). (D) Summary of changes in tumor volumes after tamoxifen treatment in $p 53^{\text {neo/R172H }} C r e-E R^{T M}$

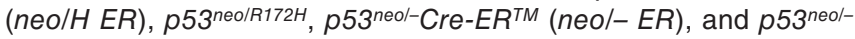
mice. L1-17, lymphomas numbered 1-17; S1-15, sarcomas numbered 1-15 (see Supplemental Table 1). (E) Survival of $p 53^{\text {neo/R172H }}$ Cre- $E R^{T M}$ $(n=8), p 53^{\text {neo/R172H }}(n=8), p 53^{\text {neol- }} C r e-E R^{T M}(n=8)$, and $p 53^{\text {neol- }}(n=8)$ mice after tamoxifen treatment, regardless of tumor types.

for 4 weeks, it was then imaged again. Otherwise, a second image was taken before the mouse was euthanized. Tumor volumes were calculated from a sequence of MRI images, and the change in tumor volume was calculated as a percentage of the original tumor volume at the time of detection. In the $p 53^{\text {neo/- } C r e-E R^{T M}}$ mice, tamoxifen treatment caused tumor regression, as previously reported for other p53 restoration models (12-14). All 8 tamoxifen-treated $p 53^{\text {neo/- } C r e-E R} R^{T M}$ mice (4 lymphomas and 4 sarcomas) showed tumor regression, ranging from $18.3 \%$ to $98.9 \%$ (Figure 3, $A$ and D, and Supplemental Table 2). We confirmed that this effect was caused by p53 restoration, not tamoxifen itself, as control $p 53^{\text {neo- }}$ mice (3 lymphomas and 5 sarcomas) showed rapid progression within 3 weeks despite tamoxifen treatment (Figure 3D and Supplemental Table 2). Tumor volumes increased from as little as $67.3 \%$ to as much as $387.9 \%$.

In $p 53^{\text {neo } / R 172 H} C r e-E R^{T M}$ mice that express mutant $\mathrm{p} 53$, p53 restoration did not cause tumor regression but halted tumor growth. All $8 p 53^{\text {neo } / R 172 H} C r e-E R^{T M}$ tumors $(5$ lymphomas and 3 sarcomas) showed little or no growth $(<45 \%)$ after weekly injections of tamoxifen (Figure 3, B and D, and Supplemental Table 2). In contrast, the $p 53^{\text {neo/R172H }}$ control tumors (5 lymphomas and 3 sarcomas) showed rapid growth, with tumor volumes ranging from $145.3 \%$ to $1,036.4 \%$ within 2 weeks (Figure 3, C and D, and Supplemental Table 2). Moreover, after tamoxifen treatment, $62.5 \%$ of $p 53^{\text {neo/R172H }} C r e-E R^{T M}$ mice and $75.0 \%$ of $p 53^{\text {neo- }-C r e-E R^{T M}}$ mice survived to the fourth week, whereas all $p 53^{\text {neo/R172H }}$ and $p 53^{\text {neo/- }}$ control mice died within 3 weeks (Figure $3 \mathrm{E}$ ). This effect on survival occurred regardless of tumor size at the onset of treatment.

To exclude the possibility that the phenotypic differences observed in $p 53^{\text {neo } / R 172 H} C r e-E R^{T M}$ and $p 53^{\text {neo/- }} C r e-E R^{T M}$ mice might simply be explained as differences in efficiency of $p 53^{\text {neo }}$ recombination, we examined the levels of the remaining $p 53^{\text {neo }}$ allele in tumors after $p 53^{\text {neo }}$ recombination, using a genomic DNA realtime PCR strategy. Since these tumors contained $1 p 53^{\text {neo }}$ allele originally, the measurement of the remaining level of the $p 53^{\text {neo }}$ allele after tamoxifen treatment will denote the efficiency of the $p 53^{\text {neo }}$ recombination in these tumors. The average levels of $p 53^{\text {neo }}$ remaining in the $p 53^{\text {neo/ }-C r e-E R^{T M}}$ and $p 53^{\text {neo/ } / R 172 H} C r e-E R^{T M}$ lymphomas after tamoxifen treatment were similar $(52.1 \%$ and $53.5 \%$, respectively; $P=0.87$ ), suggesting no significant difference in $p 53^{\text {neo }}$ recombination in these tumors (Supplemental Figure 5). Another concern is that the presence of the Cre-ERTM transgene may promote tumorigenesis in mice. We therefore compared the survival of the $p 53^{\text {neo/R172H }}$ and the $p 53^{\text {neo/R172H }} C r e-E R^{T M}$ mice without treatment. The overlapping survival curves between these 2 cohorts suggest that the Cre-ERTM transgene did not contribute to tumorigenesis in the $p 53^{\text {neo/R172H }} C r e-E R^{T M}$ mice (Supplemental Figure 6).

Apoptosis and senescence contribute to tumor suppression upon p53 restoration. To determine the mechanism(s) responsible for tumor suppression, we compared tumor response with and without p53 restoration. After 4 weekly tamoxifen injections, apoptosis was elevated in both $p 53^{\text {neo/- } C r e-E R^{T M}}$ (3 samples) and $p 53^{\text {neo/R172H }} C r e-E R^{T M}$ lymphomas (5 samples) compared with that in lymphomas without Cre-ER $R^{T M}$ (8 samples) (Figure 4, A and B). The $p 53^{\text {neo/R172H }} C r e-E R^{T M}$ tumors appeared to have an increased apoptosis response to tamoxifen as compared with $p 53^{\text {neo/- }} C r e-E R^{T M}$ tumors. However, $p 53^{\text {neo/- }}$ mice with lymphomas lived significantly longer than $p 53^{\text {neo/R172H }}$ mice with lymphomas (Supplemental Figure 7). Remarkably, in addition to apoptosis, 3 out of the $5 p 53^{\text {neo } / R 172 H} C r e-E R^{T M}$ lymphomas, but none of the $p 53^{\text {neo- }-C r e-E R^{T M}}$ lymphomas, showed induction of senescence, as detected by senescence-associated $\beta$-galactosidase (SA- $\beta$-gal) activity (Figure $4 \mathrm{~A}$ ). This phenotype was also observed in lymphomas that were collected 3 days after a single dose of tamoxifen. Four out of these six $p 53^{\text {neo/R172H }} C r e-E R^{T M}$ lymphomas showed induction of senescence, as detected by SA- $\beta$-gal assays and immunohistochemistry with senescence markers PML and DcR2 (Supplemental Figure 8). Therefore, the restored p53 activated both apoptosis and senescence programs in lymphomas from $p 53^{\text {neo/R172H }} \mathrm{Cre}-E R^{T M}$ mice. Additionally, immunohistochemistry revealed lower levels of proliferation markers Ki-67 and phospho-histone 3 in Cre-ER ${ }^{T M}$-positive lymphomas than in Cre-ER ${ }^{T M}$-negative controls (Figure 4, A and B), indicating that p53-induced apoptosis and/or senescence decreased tumor cell proliferation.

In $p 53^{\text {neo/- } C r e-E R} R^{T M}$ ( 3 samples) and $p 53^{\text {neo/R172H }} C r e-E R^{T M}$ (3 samples) angiosarcomas, the major tumor response after tamoxifen treatment was senescence, as detected by SA- $\beta$-gal staining (Figure 5A). However, in other sarcomas, such as giant-cell sarcoma and spindle-cell sarcoma, both apoptosis and senescence were detected (Supplemental Figure 9 and data not shown). The tamoxifentreated $p 53^{\text {neo } /-}$ Cre-ER $E R^{T M}$ angiosarcomas also showed less tumor cell proliferation than the $C r e-E R^{T M}$-negative control tumors (7 samples) (Figure 5, A and B). Thus, the p53-induced antitumor activities suppressed tumor growth in different tumors by different and sometimes overlapping mechanisms. We next addressed the role of the innate immune system in tumors after p53 reactivation in angiosarcomas. Inflammatory cell infiltration in tumors of different genotypes was determined by counting the number of polymorphonuclear cells and lymphocytes in areas devoid of focal inflammatory aggregates. $p 53^{\text {neo/- }}$ and $p 53^{\text {neo/R172H }}$ tumors harbored a slightly higher (although insignificant) number of interstitial inflammatory cells compared with that in their respective $p 53^{\text {neo/- } C r e-E R} R^{T M}$ and $p 53^{\text {neo/ } R 172 H} C r e-E R^{T M}$ tumor counterparts (Supplemental Figure 10). Histological analysis also revealed that $p 53^{\text {neo/- }}$ and $p 53^{\text {neo/R172H }}$ tumors had occasional focal inflammatory aggregates that were rare or absent in $p 53^{\text {neo/- }} \mathrm{Cre}-E R^{T M}$ and $p 53^{\text {neo } / R 172 H} \mathrm{Cre}-E R^{T M}$ tumors. 
A

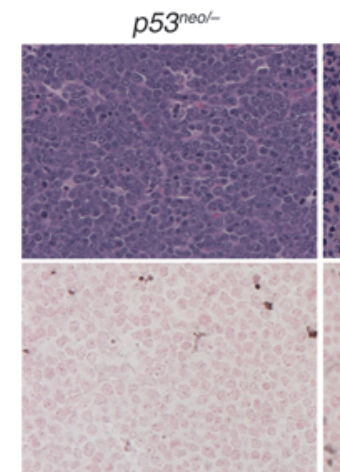

p53 ${ }^{\text {neo- }}$ Cre-ER
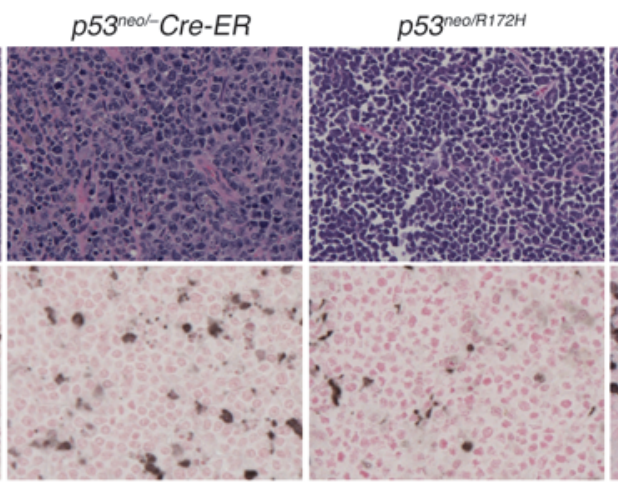

p5 $3^{\text {neo/R172H }}$ Cre-ER
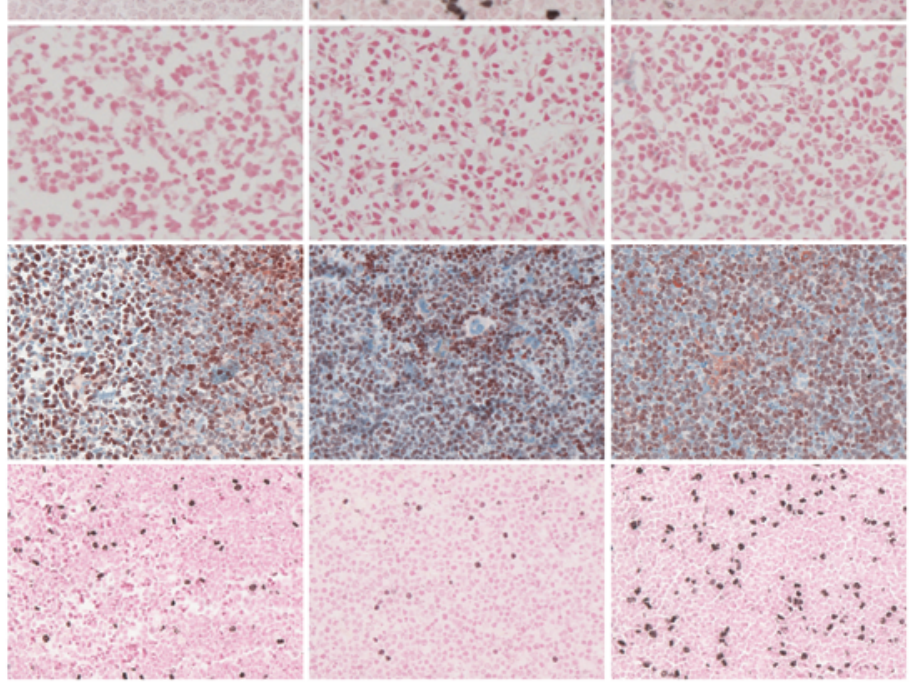

B
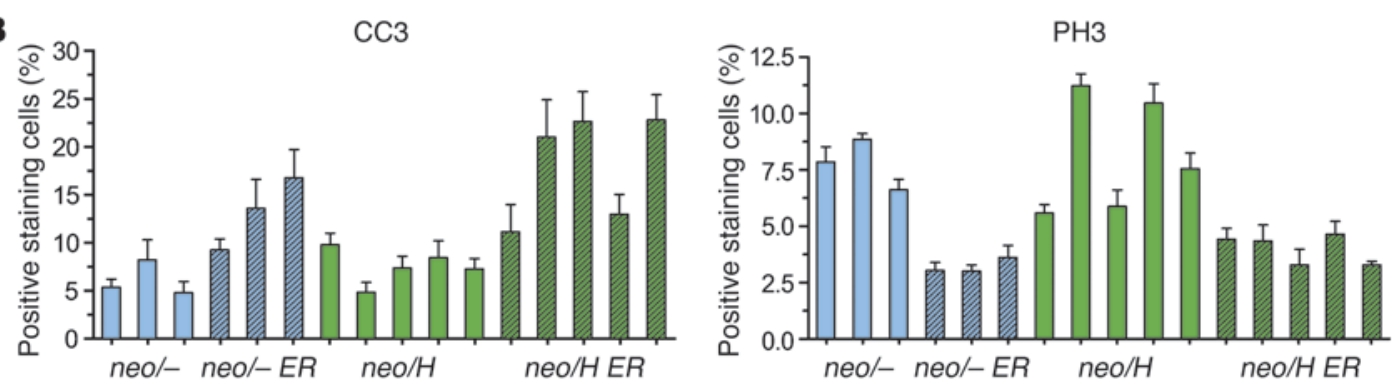

Figure 4

p53 restoration resulted in elevated apoptosis and induction of senescence in lymphomas and decreased tumor cell proliferation. Tamoxifentreated lymphomas collected in the MRI study were subjected to H\&E staining; immunohistochemical staining for cleaved caspase-3, Ki-67, and phospho-histone 3 (PH3); and SA- $\beta$-gal assays. (A) Images of analyses of the representative lymphomas from the tamoxifen-treated $p 53^{\text {neol-}}$, $p 53^{\text {neol-Cre-E}} E R^{T M}, p 53^{\text {neo/R172H }}$, and $p 53^{\text {neo/R172H }}$ Cre-ER $R^{T M}$ mice. Scale bar: $100 \mu \mathrm{m}$. (B) Percentages of cells staining positive for cleaved caspase-3 and phospho-histone 3 in A. Positive cells were counted in 4 random fields (original magnification, $\times 40$ ) and presented as the mean \pm SEM.

p53 response upon restoration in tumors. To monitor $\mathrm{p} 53$ reactivation in tumors upon initial tamoxifen treatment, we performed biopsies to harvest tumor tissue from mice bearing visible subcutaneous tumors. We compared the effect of wild-type p53 restoration in tumors from $p 53^{\text {neo/- } C r e-E R ~} E R^{T M}$ mice with those from $p 53^{\text {neo/R172H }} C r e-E R^{T M}$ mice. In $p 53^{\text {neo/-C } C r e-E R^{T M}}$ spindle-cell sarcomas ( 2 samples), p53 and p21 levels were elevated as early as 1 day after tamoxifen treatment. The highest levels of p53-induced apoptosis were observed 3 days after tamoxifen treatment (Figure 6, A and C). In $p 53^{\text {neo/R172H }} \mathrm{Cre}-E R^{T M}$ spindle-cell sarcomas (2 samples), immunohistochemistry revealed increased p53 levels 1 day after tamoxifen treatment (we cannot distinguish between wild-type and mutant p53 staining). Moreover, in the same tumors, p21 levels were elevated after tamoxifen treatment, suggesting wild-type p53 activity. Apoptosis was also induced in these tumors but to a lesser degree than in $p 53^{\text {neo- }-} \mathrm{Cre}-E R^{T M}$ tumors (Figure 6, B and C). In a $p 53^{\text {neo/- }}$ Cre-ER $R^{T M}$ angiosarcoma, the tumor showed elevated p53 and p21 levels when examined at day 3 after tamoxifen treatment, and the restored p53 also activated senescence as revealed by SA$\beta$-gal staining (Supplemental Figure 11). In a $p 53^{\text {neo/R172H }} C r e-E R^{T M}$ angiosarcoma, p53 and p21 were also elevated 3 days after tamoxifen treatment. However, fewer cells were senescent upon p53 restoration in the $p 53^{\text {neo/R172H }} \mathrm{Cre}-E R^{T M}$ angiosarcoma than in the $p 53^{\text {neo/- }} \mathrm{Cre}-E R^{T M}$ angiosarcoma (Supplemental Figure 11). These data suggest that 


\section{A}
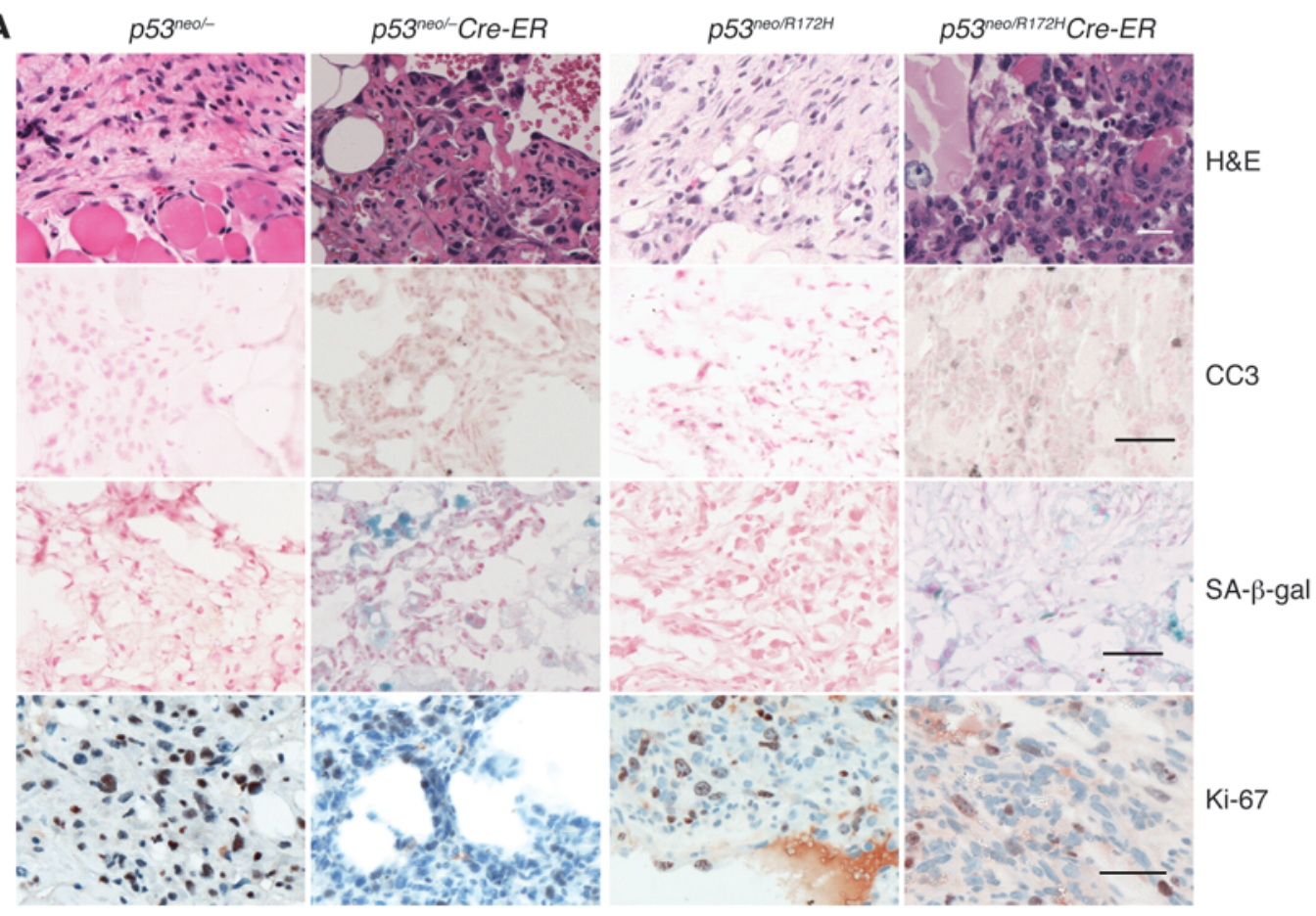

B
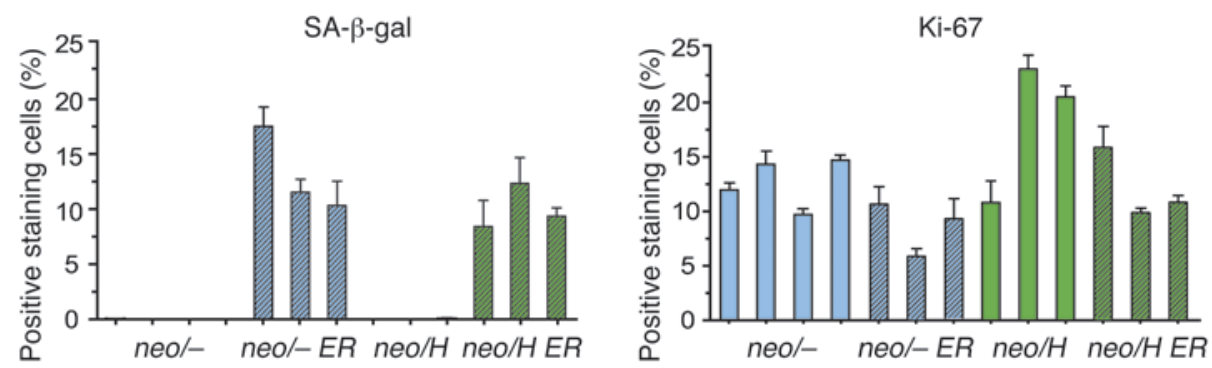

Figure 5

p53 restoration resulted in induction of senescence in angiosarcomas and decreased tumor cell proliferation. Tamoxifen-treated angiosarcomas collected in the MRI study were subjected to H\&E staining; immunohistochemical staining for cleaved caspase-3 (CC3), Ki-67, senescenceassociated $\beta$-galactosidase (SA- $\beta$-gal assays). (A) Images of analyses of the representative angiosarcomas from tamoxifen-treated $p 53^{\text {neol-}}$,

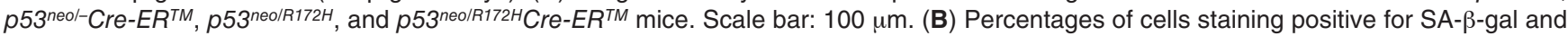
$\mathrm{Ki}-67$ in A. Positive cells were counted in 4 random fields (original magnification, $\times 40$ ) and presented as the mean \pm SEM.

the restored wild-type p53 was activated in tumors after the initial tamoxifen injection and that p53 restoration led to lower level of p53 activation in the $p 53^{\text {neo } / R 172 H} C r e-E R^{T M}$ tumors than that in the p53 $3^{\text {neo- }-C r e-E R} R^{T M}$ tumors.

p53R172H dampens the activity of the restored wild-type p53. To explore the antagonizing effect of p53R172H on the restored wildtype $\mathrm{p} 53$, we collected angiosarcomas from the $p 53^{\text {neo } / R 172 H} C r e-E R^{T M}$ and $p 53^{\text {neo- }-C r e-E R^{T M}}$ mice 3 days after tamoxifen treatment. First, we compared recombination at the $p 53^{\text {neo }}$ allele in these tumors using genomic DNA and real-time PCR. Recombination of $p 53^{\text {neo }}$ was comparable in the $p 53^{\text {neo/ } / 172 H} C r e-E R^{T M}$ and the $p 53^{\text {neo/- }} \mathrm{Cre}-E R^{T M}$ tumors $(P=0.97$; Supplemental Figure 12). Despite similar recom-

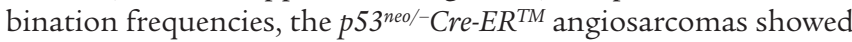
more cells with a senescent phenotype than the $p 53^{\text {neo/R172H }} C r e-E R^{T M}$ angiosarcomas, as detected by SA- $\beta$-gal assays and immunohistochemistry of senescence markers p16 and Dec1 $(P=0.019, P=0.032$, and $P=0.043$, respectively; Figure $7, A$ and $B)$. Expression of $p 21$ and cyclin G1 (Ccng1), 2 p53 target genes, was also enhanced in the $p 53^{\text {neo/- }} \mathrm{Cre}-E R^{T M}$ angiosarcomas relative to that in the $p 53^{\text {neo } / R 172 H} C r e-E R^{T M}$ angiosarcomas $(P=0.0033$ and $P=0.030$, respectively; Figure 7, C and D).

We also compared levels of p53 activation in isogenic $p 53^{\text {neo/R172H }} C r e-E R^{T M}$ and $p 53^{\text {neo/- } C r e-E R^{T M}} \mathrm{MEFs}$ treated with 4-hydroxy-tamoxifen (to recombine the $p 53^{\text {neo }}$ allele) and with doxorubicin (to activate p53). Cells from both genotypes had similar $p 53^{\text {neo }}$ recombination frequencies, but $p 53^{\text {neo/- } C r e-E} R^{T M}$ MEFs have a higher level of p53 target gene expression ( $p 21$, Cong1, and p53 up-regulated modulator of apoptosis [puma]) than $p 53^{\text {neo } / R 172 H}$ Cre-ER $E R^{T M}$ MEFs (Supplemental Figure 13). In both tumors and MEFs, p53 levels were also upregulated, although we cannot distinguish between wild-type and mutant p53 proteins using Western blots (Figure 7D and Supplemental Figure 13). To determine whether the p53R172H mutant binds to wild-type p53, we transfected His-tagged wild-type p53 in $p 53^{\text {neo } /-} C r e-E R^{T M}$ and $p 53^{\text {neo/R172H }} C r e-E R^{T M}$ sarcoma tumor cell lines that were established from untreated 
A
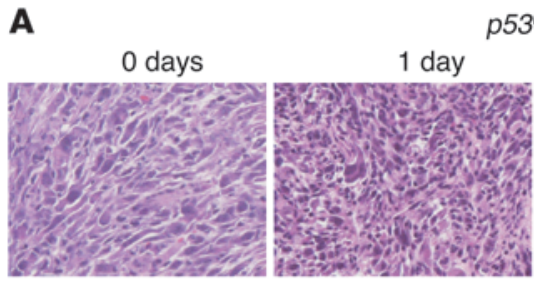

p53 ${ }^{\text {neo/-Cre-ER }}$
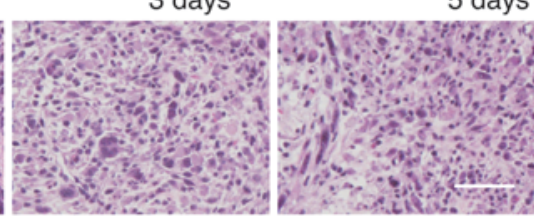

$H \& E$
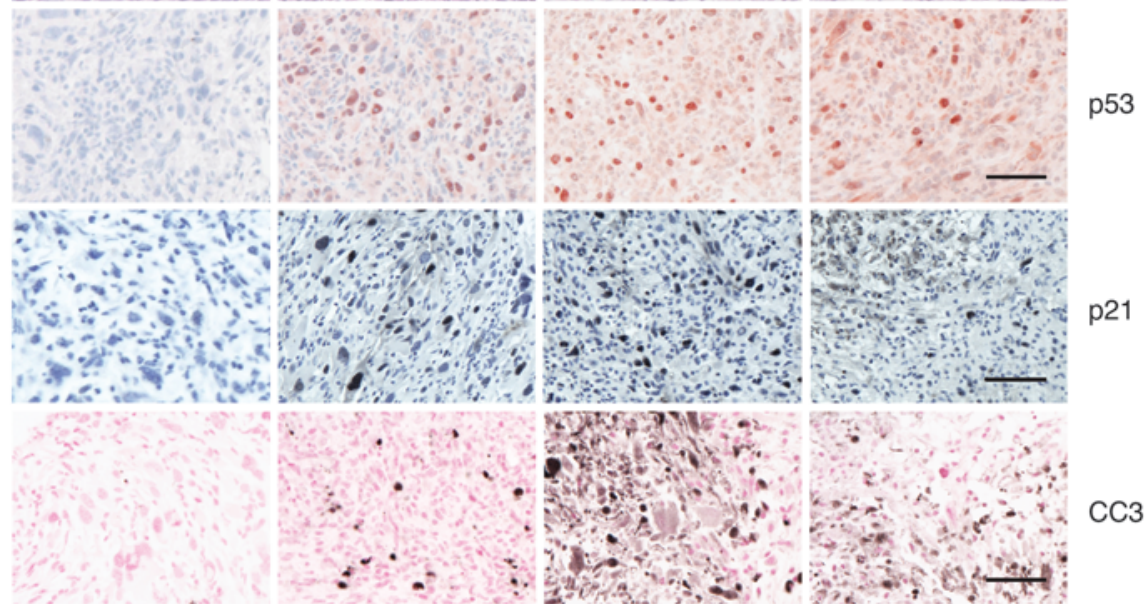

B

0 days
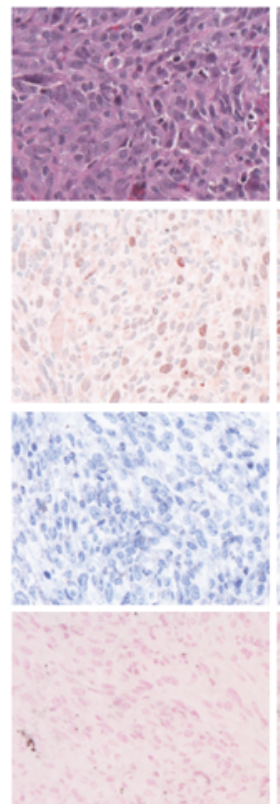

1 day
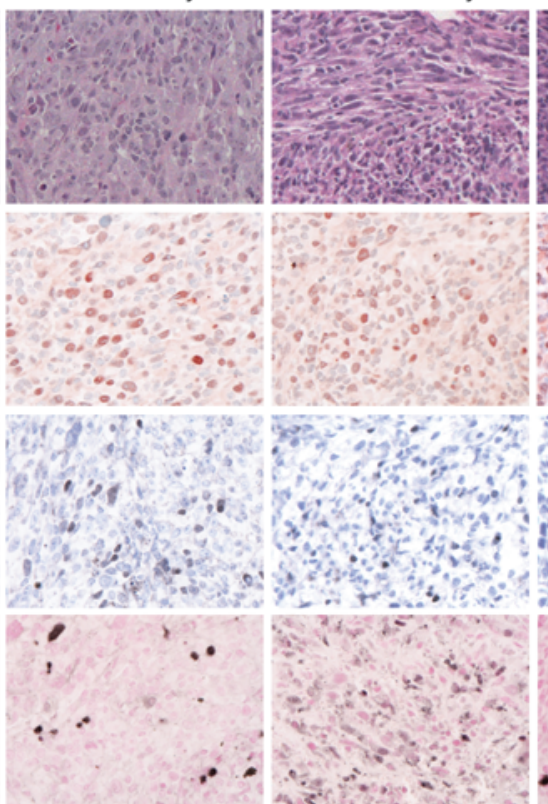

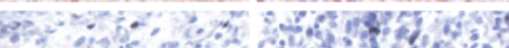

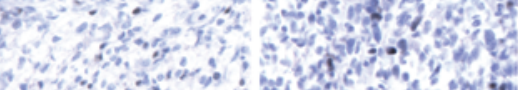

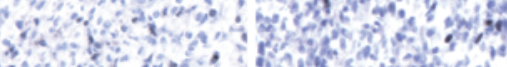
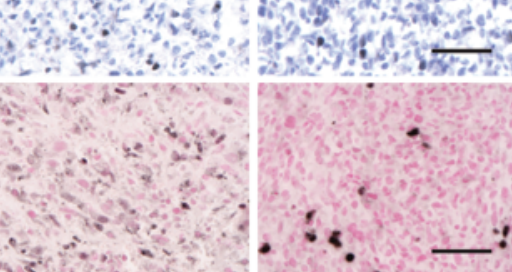

$\mathrm{CC} 3$

\section{Figure 6}

Activation of wild-type p53 in tumors after tamoxifen treatment. Tumor biopsy specimens harvested from the $p 53^{\text {neol- }}$ Cre-ERTM and $p 53^{\text {neo/R172H }}$ Cre-ERTM mice, before (day 0) and 1,3 , and 5 days after tamoxifen treatment (day 1, 3, and 5), were subjected to $\mathrm{H} \& \mathrm{E}$ staining and immunohistochemical staining for p53, p21, and cleaved caspase-3. (A) Images of analyses of biopsies from a representative spindle-cell sarcoma in a p53 ${ }^{\text {neol-Cre-ER }}$ TM $^{T M}$ mouse (day 0, 1, 3, and 5). Scale bar: $100 \mu \mathrm{m}$. (B) Images of analyses of biopsies from a representative spindle-cell sarcoma in a $p 53^{\text {neo } / R 172 H} \mathrm{Cre}-E R^{T M}$ mouse (day 0, 1, 3, and 5). Scale bar: $100 \mu \mathrm{m}$. (C) Percentages of cells staining positive for p53, p21, and cleaved caspase-3 in A and $\mathbf{B}$. Positive cells were counted in 4 random fields (original magnification, $\times 40$ ) and presented as the mean \pm SEM. Statistical significance between tumors with different genotypes was calculated using the $t$ test, and the $P$ value is less than 0.05 for $\mathrm{p} 21$ and cleaved caspase-3 at day 3 and day 5 .

\section{C}

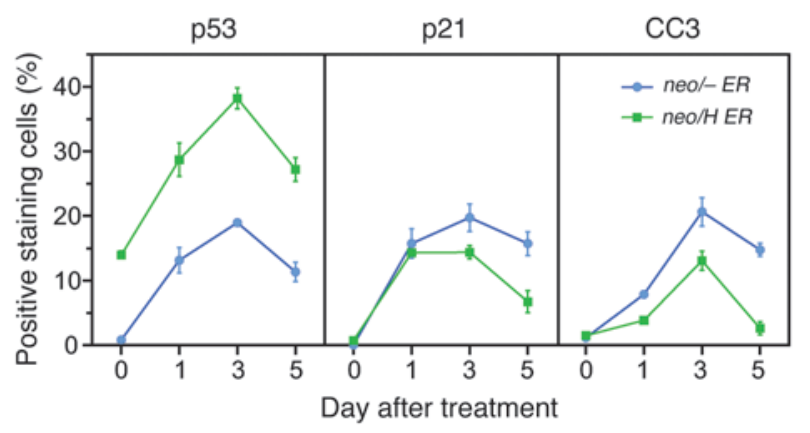


mice and then immunoprecipitated the p53 complex with the mutant p53-specific antibody, PAb240, that recognizes the mutant p53 conformation. As shown in Supplemental Figure 14, the p53R172H mutant bound His-tagged wild-type p53. To examine direct $\mathrm{p} 53$ binding to $p 21$ and puma promoters, we performed ChIP experiments in the above $p 53^{\text {neo/R172H }} C r e-E R^{T M}$ and $p 53^{\text {neo/-C }}$ Cre-ER $R^{T M}$ sarcoma tumor cell lines. After 4-hydroxytamoxifen treatment, both cell lines showed similar $p 53^{\text {neo }}$ recombination frequencies (Figure 7E). Reproducibly, p53 bound to the p21 but not to the puma promoter (Figure 7F). More importantly, the $p 53^{\text {neo/-C}} \mathrm{Cre}-E R^{T M}$ tumor cells showed more 53 binding to the $p 21$ promoter than $p 53^{\text {neo } / R 172 H} C r e-E R^{T M}$ tumor cells (Figure $7 \mathrm{~F}$ ). These data were consistent with increased expression of $p 21$ but not puma (Figure 7G). Thus, p53R172H dampened the activity of restored wild-type p53 through inhibition of wild-type p53 transcriptional activity.

\section{Discussion}

In this study, we engineered a mouse model in which we restored wild-type p53 in tumors that contained a p53 missense mutation, since most human cancers harbor P53 missense mutations with gain-of-function and dominant-negative activity. In these mice, p53 restoration led to delayed tumor growth. The delay in tumor growth predicts a positive therapeutic effect of $\mathrm{p} 53$ restoration in 553 mutant tumors.

Tumor regression in our $p 53^{\text {neo- }-C r e-E R^{T M}}$ mice was consistent with that in previous reports, even though only 1 copy of the wildtype $p 53$ allele was restored in our mice (13). The restored wildtype p53 induced apoptosis and senescence in tumors, indicating that the p53 pathway is reactivated in tumors and that absence of p53 is required for maintenance of the tumor phenotype. We also observed that tumor response to p53 restoration was tumor-type specific. p53 restoration mainly induced apoptosis in lymphomas and senescence in angiosarcomas. However, p53 restoration induced both apoptosis and senescence in giant-cell and spindlecell sarcomas. An understanding of the mechanisms that trigger apoptosis or senescence should lead to better therapies.

Unlike the tumor regression phenotype observed in $p 53^{\text {neo/- }} \mathrm{Cre}$ $E R^{T M}$ mice, we found arrested tumor growth in the $p 53^{\text {neo/ } / R 172 H} C r e-$ $E R^{T M}$ mice after $\mathrm{p} 53$ restoration, suggesting a dominant-negative effect of the $p 53^{R 172 H}$ mutation in vivo. The dominant-negative effect was first shown in in vitro cotranslation experiments, in which mutant p53 drove wild-type p53 into an inactive conformation after hetero-oligomerization (18). Hetero-oligomerization prevents wild-type p53 from binding to its target DNA sequence $(19,20)$. In the present study, the $p 53^{\text {neo } / R 172 H}$ mice had survival times similar to those of the $p 53^{-/-}$and $p 53^{R 172 H /-}$ mice, indicating that the $p 53^{R 172 H}$ allele completely dominated the hypomorphic $p 53^{\text {neo }}$ allele. Therefore, the p53R172H mutant effectively abrogates the activity of the small amount of wild-type p53 expressed by the $p 53^{\text {neo }}$ allele but can not completely abolish normal levels of wild-type p53 activity, as indicated by the fact that $p 53^{+/-}$and $p 53^{+/ R 172 H}$ mice share similar survival curves.

Overexpression of mutant p53 shows a dominant-negative effect in cultured tumor cell lines (21-24). Here we demonstrated that the p53R172H mutant partially inhibited the activity of the restored wild-type p53 in tumors. Unlike the short-lived wildtype $\mathrm{p} 53$ protein, $\mathrm{p} 53 \mathrm{R} 172 \mathrm{H}$ is stabilized and accumulates to a high level in tumors (10). The stabilized mutant p53 increases the probability that hetero-oligomers form between the wild-type and the mutant p53, which would result in loss of the wild-type p53 activities. However, in our study, the restored wild-type p53 was not overwhelmed, as evidenced by the fact that in $p 53^{R 172 H}$ tumors, p53 retained some activity. We hypothesize that some wild-type p53 escaped from binding the mutant p53 and formed functional homo-tetramers.

Inactivation of wild-type p53 by the p53R172H mutant reduced levels of p53 activation in tumors after p53 restoration, as shown by the lower levels of apoptosis and senescence in $p 53^{\text {neo/R172H }} \mathrm{Cre}-E R^{T M}$ tumors than in $p 53^{\text {neo/- }} \mathrm{Cre}-E R^{T M}$ tumors. Interestingly, we observed senescence in $p 53^{\text {neo/R172H }} \mathrm{Cre}-E R^{T M}$ lymphomas but not in $p 53^{\text {neo/-C}}$ Cre-ER $R^{T M}$ lymphomas. This may be dose dependent, as stochastic assembly of fewer wild-type p53 tetramers may lead to senescence not apoptosis. In vitro studies suggest that the intracellular level of activated p53 affects promoter binding and transactivation $(25,26)$. A high level of active p53 initiates apoptosis because low-affinity p53 binding sites present in promoters of apoptosis-related genes are activated. On the other hand, p53, when present at low levels, binds only high-affinity sites present in promoters of genes involved in cell cycle arrest (27-29). Therefore, in $p 53^{\text {neo- }-C r e-E R^{T M}}$ lymphomas, the restored wild-type $\mathrm{p} 53$, in the absence of mutant p53, insured the activation of apoptosis. However, in $p 53^{\text {neo } / R 172 H} C r e-E R^{T M}$ lymphomas, the decreased level of p53 activation caused by the dominant-negative effect of mutant p53 may have promoted the transactivation of genes involved in cell cycle arrest and senescence.

Our studies have revealed a dosage-dependent effect of p53induced tumor suppression in vivo. First, the small amount of wild-type p53 expressed by the hypomorphic $p 53^{\text {neo }}$ allele delayed tumor onset and resulted in a shift in tumor spectrum toward sarcomas. Second, the decreased level of the functional wild-type p53 in the $p 53^{R 172 H}$ tumors led to arrested tumor growth but not tumor regression. We therefore speculate that excessive wild-type $\mathrm{p} 53$ will increase the level of functional p53 over that of mutant p53. The goal of $p 53$ gene transfer in clinical trials is to achieve overexpression of wild-type p53 in human cancers (30). Our findings in mice lead us to speculate that this strategy could lead to tumor regression in humans. Likewise, other strategies, such as the use of the chemical drug PRIMA to restore the mutant p53 to a wild-type competent conformation, may synergize with restoration of wildtype p53, leading to tumor regression (31).

The use of genetically engineered mouse models bypasses some difficulties confronted by clinicians in designing $p 53$ gene therapy. First, p53 restoration in mouse models is a one-hit genetic event that is guaranteed to happen. Second, the wild-type p53 is produced endogenously by a modified $p 53$ locus, ignoring any delivery blockades that hinder P53 gene transfer into tumor cells of human patients. Additionally, some human cancers containing no P53 mutations may tolerate wild-type p53 restoration. These may account for the limited effectiveness of P53 gene therapy that has been thus far realized in clinical trials (32-36). Nevertheless, our results, together with those from previous studies, emphasize the potential therapeutic efficacy of p53 restoration in human cancer treatment. Specifically, the most important implication of the current findings is that p53 restoration has therapeutic potential in human cancers with P53 missense mutations, not just loss of P53.

\section{Methods}

Mice. The $p 53^{\text {neo }}$ allele was generated in our laboratory using the same strategies as we used to generate the $p 53^{R 172 H}$ allele (also designated 

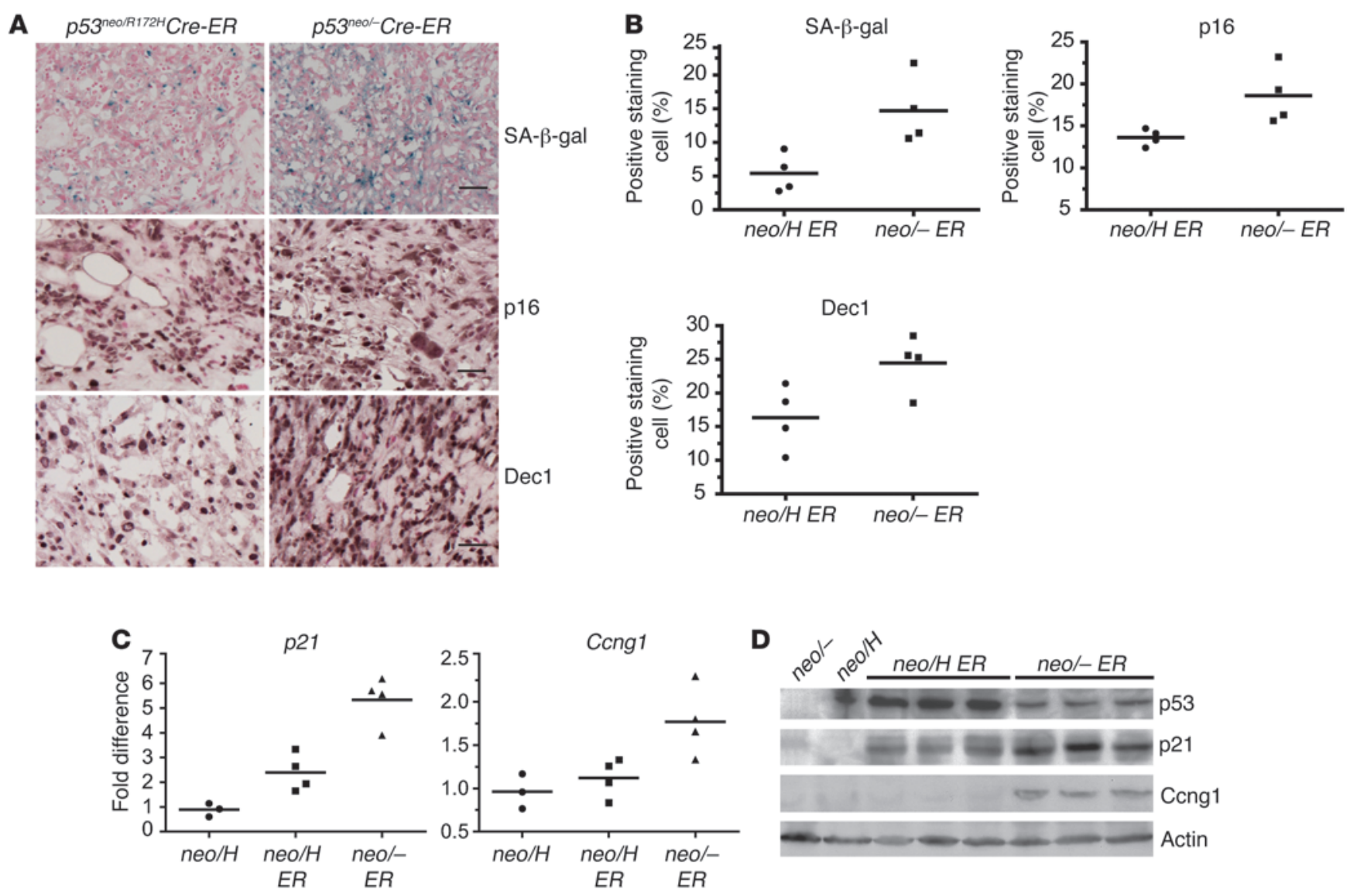

D
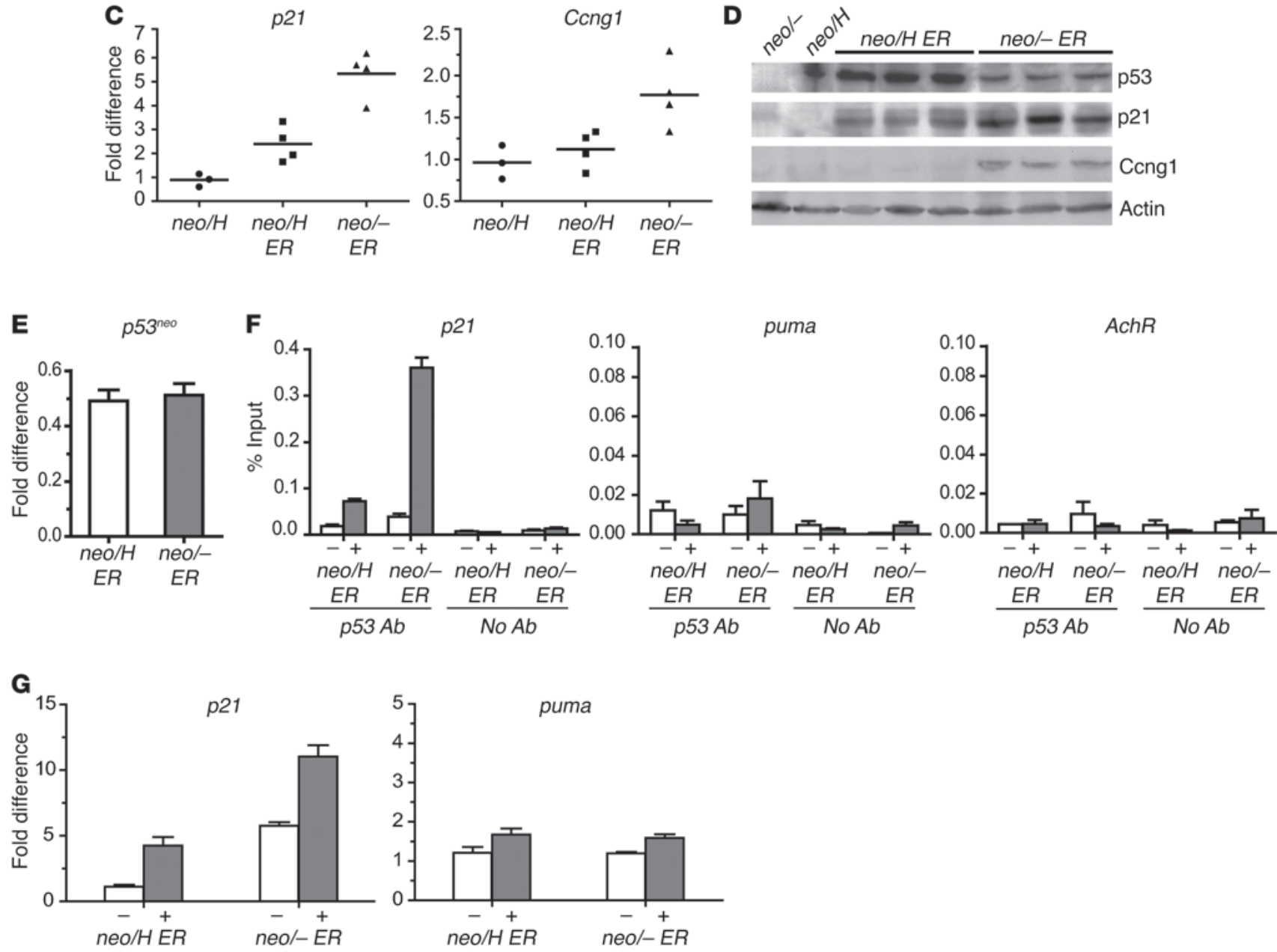


\section{Figure 7}

p53R172H dampened the transcription activity of the restored wildtype p53. (A) Representative images of SA- $\beta$-gal assays and $p 16$ and Dec1 staining of tamoxifen-treated $p 53^{\text {neol- }}$ Cre-ER $E R^{T M}$ and $p 53^{\text {neo/R172H }}$ Cre-ER ${ }^{T M}$ angiosarcomas. Scale bar: $100 \mu \mathrm{m}$. (B) Percentage of SA$\beta$-gal-, p16-, and Dec1-positive staining cells in p53 ${ }^{\text {neol- }} \mathrm{Cre}-E R^{T M}$ and $p 53^{\text {neo/R172H }} \mathrm{Cre}-E R^{T M}$ angiosarcomas. (C) Comparison of mRNA lev-

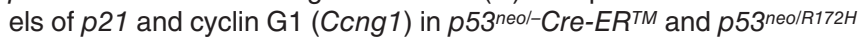
Cre-ERTM angiosarcomas using real-time RT-PCR. $p 53^{\text {neo/R172H }}$ cells without Cre-ERTM were used as controls. (B and C) Horizontal bars indicate the mean, and symbols indicate individual angiosarcomas. (D) Western blot analyses of p53, p21, and cyclin G1 (Ccng1) protein levels in control and tamoxifen-treated tumors. Protein levels were normalized to actin. (E) Recombination in $p 53^{\text {neol- }} \mathrm{Cre}-E R^{T M}$ and $p 53^{\text {neo/R172H }}$ Cre-ER $R^{T M}$ tumor cell lines after 4-hydroxy-tamoxifen treatment. The results are presented as the mean \pm SEM of 3 assays. (F) Comparison of DNA binding by p53 to $p 21$ and puma promoters

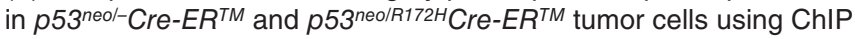
assays. The acetylcholine receptor $(A c h R)$ promoter was used as a control, and the results are presented as percentage of input. Data are representative of 2 ChIP experiments performed in triplicate. (G)

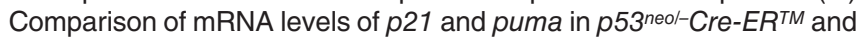
$p 53^{\text {neo/R172H }} \mathrm{Cre}-E R^{T M}$ tumor cells with (+) and without (-) 4-hydroxytamoxifen treatment, using real-time RT-PCR analysis. The results are presented as the mean \pm SEM of 3 assays.

$p 53^{R 172 H}$ ref. 7), except that no $p 53^{R 172 H}$ mutation was engineered in the $p 53^{\text {neo }}$ allele (7). Chimeric mice carrying the $p 53^{\text {neo }}$ allele were generated in Genetically Engineered Mouse Facility of The University of Texas MD Anderson Cancer Center and were crossed with C57BL/6 mice from the National Cancer Institute for more than 5 generations, so that the genetic background of the mice was greater than $95 \% \mathrm{C} 57 \mathrm{BL} / 6$. The $p 53^{\text {neo/ }}$ mice were crossed with $Z P 3$-Cre transgenic mice to generate $p 53^{\Delta n e o /+}$ mice. Genotyping was performed by PCR analysis using primers surrounding the loxP site and 1 primer in the neo cassette. The $p 53^{\text {neo/neo }}$ mice were crossed with $p 53^{R 172 H / R 172 H}$ and $p 53^{-/-}$mice to generate $p 53^{\text {neo/R172H }}$ and $p 53^{\text {neo/- }}$ mice. The $p 53^{\text {neo/neo }}$ mice were crossed with $C r e-E R^{T M}$ transgenic mice to generate $p 53^{\text {neo/ }+} C r e-E R^{T M}$ mice, which were intercrossed to generate $p 53^{\text {neo/neo }} \mathrm{Cre}-E R^{T M}$ mice. The $p 53^{\text {neo } / \text { neo }} \mathrm{Cre}-E R^{T M}$ mice were crossed with $p 53^{R 172 H / R 172 H}$ and $p 53^{-/-}$mice to generate $p 53^{\text {neo/- }} C r e-E R^{T M}$ and $p 53^{\text {neo/R172H }} C r e-E R^{T M}$ mice. The mice were bred and maintained in the MD Anderson mouse facility in accordance with institutional guidelines. Animal studies were approved by the Institutional Animal Care and Use Committee of The University of Texas MD Anderson Cancer Center.

Southern blotting. Southern blot analyses were performed as previously described (7). A specific DNA probe spanning exons 3 and 4 was used for hybridization with both the $p 53^{\text {neo }}$ and $p 53^{\Delta \text { neo }}$ alleles but not the $p 53$ null allele. The PhosphorImager (Molecular Dynamics) was used to measure radioactive intensity on the membrane used in Southern blotting.

Tamoxifen treatment. Tamoxifen (Sigma-Aldrich) was dissolved in corn oil to a concentration of $30 \mathrm{mg} / \mathrm{ml}$. After tumors were detected, the mice were treated with tamoxifen by intraperitoneal injection at a dose of $3 \mathrm{mg}$ per 40 g of body weight.

MRI analysis. Anesthesia was induced using 5\% isoflurane in oxygen and maintained using 1\%-3\% isoflurane in oxygen. Anesthesia levels were monitored using respiratory bellows in conjunction with a small-animal physiological monitoring system (Small Animal Instruments Inc.). All magnetic resonance images were acquired using a 7T BioSpec small-animal imaging system (Bruker Biospin MRI) and imaging gradients with a $60-\mathrm{mm}$ inside diameter. A linear volume resonator (35- $\mathrm{mm}$ inside diameter) was used for signal excitation and detection. Scout images to verify animal positioning were followed by coronal $\mathrm{T}_{2}$-weighted rapid acquisi- tion with relaxation enhancement (RARE) scans (echo time/repetition time, $65 \mathrm{~ms} / 5,000 \mathrm{~ms}$; $40-\mathrm{mm} \times 30$-mm field of view; $256 \times 192$ voxels image matrix was zero filled to $256 \times 256$ voxels; 1 -mm slice thickness with 0.25 skip; RARE factor $12 ; 4$ averages). Tumor volumes (in $\mathrm{cm}^{3}$ ) were measured by segmentation of $\mathrm{T}_{2}$-weighted coronal and axial image stacks using ParaVision 4.0 software (Bruker Biospin MRI).

Histology and immunohistochemistry. Normal and tumor mouse tissues were collected and processed for histological analysis as previously described (7). Fresh tumor biopsy specimens were collected from mice with subcutaneous tumors under anesthesia, using a $1.5-\mathrm{mm}$ biopsy punch (Miltex). Immunohistochemical analyses were performed as previously described (37) on paraffin-embedded sections, using antibodies for p53 (CM5, Vector Laboratories; 1:200; and FL-393, Santa Cruz Biotechnology Inc.; 1:100), cleaved caspase-3 (Cell Signaling Technology; 1:200), Ki-67 (TEC-3, Dako; 1:50), phospho-histone 3 (Cell Signaling Technology; 1:200), p21 (SX118, Dako; 1:50), p16 (M-156, Santa Cruz Biotechnology Inc.; 1:200), PML (PG-M3, Santa Cruz Biotechnology Inc.; 1:100), Dec1 (Novus Biological; 1:200), and DcR2 (Stressgen; 1:200).

$S A-\beta$-gal assay. Tumor tissues were collected and fixed in $4 \%$ paraformaldehyde and then incubated in Hank's buffered salt solution supplemented with $10 \%, 15 \%$, or $20 \%$ of sucrose. Tissues were frozen in Optimal Cutting Temperature compound (OTC) (Sakura Finetek). SA- $\beta$-gal staining was performed as previously described on $10-\mu \mathrm{m}$ frozen sections (38).

Cell culture and Western blotting. MEFs were generated by collecting embryos at 13.5 days post coitum after crossing mice of the appropriate genotypes. The cell cultures were maintained as previously described (39). Protein extracts $(50 \mu \mathrm{g})$ from MEFs or tumor tissues were resolved on SDS-PAGE, transferred to Hybond P membrane (Amersham-Pharmacia), and incubated with primary antibodies for p53 (CM5, Vector Laboratories; 1:500; and FL-393, Santa Cruz Biotechnology Inc.; 1:100), p21 (SX118, BD Pharmingen; 1:500), cyclin G1 (c-18, Santa Cruz Biotechnology Inc.; 1:500), puma (Cell Signaling Technology; 1:1,000), and actin (SigmaAldrich; 1:2,000). After being incubated with horseradish peroxidase-conjugated secondary antibody, the proteins bound to the membrane were visualized using ECL (GE Healthcare). The intensity of the protein bands on the membrane was measured using ImageJ software (http://rsbweb. nih.gov/ij/). As for protein immunoprecipitation, after transfection, a total of $500 \mu \mathrm{g}$ of cell lysates were incubated with $50 \mu \mathrm{l}$ of protein $\mathrm{A} / \mathrm{G}$ agarose beads (Calbiochem) and $5 \mu \mathrm{g}$ of p53 PAb240 antibody (Ab-3, Calbiochem). The protein complexes were eluted with $50 \mu \mathrm{l}$ Laemmli sample buffer, resolved on SDS-PAGE, and blotted with p53 and anti-His (Cell Signaling Technology; 1:500) antibodies.

Real-time PCR. Genomic DNAs were extracted from homogenized tumor tissues after proteinase $\mathrm{K}$ digestion followed by phenol-chloroform cleanup. Total RNAs were extracted using TRIzOL (Ambion). Firststrand cDNAs were synthesized using a kit from GE Healthcare. The Primer Express program (Applied Biosystems) was used to design primer sequences. The primers used for $p 53^{\text {neo }}$ amplification were $5^{\prime}$-GCTTGCGGAACCCTTAATATAACTT-3' and 5' -GCTGTCCTGGAACTCACTTTGTAG-3', spanning the neo cassette and intron 4 of p53 locus. Real-time reverse transcription PCR and the primers for $p 21$, Ccng1, and Gapdb were previously described (40).

ChIP. ChIP assays were performed as previously described (41). The antibody used for p53 was CM5 (Vector Laboratories). Sarcoma tumor cell lines were harvested from 150-mm plates after 4-hydroxy-tamoxifen treatment for 1 day. Real-time PCR was performed in a 384-well plate using the ABI Prism 7900HT with $5 \mu 12 \times$ SYBR Green PCR Master Mix (Applied Biosystems), $1 \mu \mathrm{l}$ each of $8 \mu \mathrm{M}$ forward and reverse primers, and $3 \mu \mathrm{l}$ of the template. Primers used were $p 21,5^{\prime}$-GGCCTTCAGGAACATGTCTTG-3' and 5'-ACCACCCTGCACTGAAGCA-3'; puma, 5'-GGACG- 
GTCGCCTTGCA-3' and $5^{\prime}$-CAGCCTTAGTCCCAGTGATGAAA-3'; and acetylcholine receptor (AchR), 5'-CCTCCCCCAACTCCACTTTT-3' and 5'-GGAGGTTGGAGGGAGAAGGA-3'.

Statistics. The Prism 4 program (GraphPad Software) was used to perform statistical analysis. A $P$ value of $\leq 0.05$ was considered statistically significant. Kaplan-Meier analyses were performed to compare differences between survival curves, and 2-tailed Student's $t$ test analysis was performed to compare differences between treatment groups or individual mice before and after treatment.

\section{Acknowledgments}

This study was supported by NIH grants CA82577 and CA34936 to G. Lozano. G. Lozano is the recipient of the Mattie Allen Fair Research Chair at MD Anderson Cancer Center. We thank Sean Post for comments on the manuscript; Doug Webb, Jorge DeLacerda, and Charlie Kingsley for help with MRI; Angelito De Villa and Maurice J. Dufilho IV for help with histology; and Peirong Yang for help with animal care.

Received for publication July 26, 2010, and accepted in revised form December 1, 2010.

Address correspondence to: Guillermina Lozano, Department of Genetics, Unit 1010, The University of Texas MD Anderson Cancer Center, 1515 Holcombe Blvd., Houston, Texas 77030, USA. Phone: 713.834.6386; Fax: 713.834.6380; E-mail: gglozano@ mdanderson.org.

Tamara Terzian's present address is: Department of Dermatology, University of Colorado, Aurora, Colorado, USA.
1. Levine AJ, Finlay CA, Hinds PW. P53 is a tumor suppressor gene. Cell. 2004;116(2 suppl):S67-S69.

2. Lane DP. Exploiting the p53 pathway for the diagnosis and therapy of human cancer. Cold Spring Harb Symp Quant Biol. 2005;70:489-497.

3. Bartek J, et al. Aberrant expression of the p53 oncoprotein is a common feature of a wide spectrum of human malignancies. Oncogene. 1991; 6(9):1699-1703.

4. Greenblatt MS, Bennett WP, Hollstein M, Harris CC. Mutations in the p53 tumor suppressor gene: clues to cancer etiology and molecular pathogenesis. Cancer Res. 1994;54(18):4855-4878.

5. Petitjean A, et al. Impact of mutant p53 functional properties on TP53 mutation patterns and tumor phenotype: lessons from recent developments in the IARC TP53 database. Hum Mutat. 2007; 28(6):622-629.

6. Olive KP, et al. Mutant p53 gain of function in two mouse models of Li-Fraumeni syndrome. Cell. 2004; 119(6):847-860.

7. Lang GA, et al. Gain of function of a p53 hot spot mutation in a mouse model of Li-Fraumeni syndrome. Cell. 2004;119(6):861-872.

8. Lozano G. The oncogenic roles of p53 mutants in mouse models. Curr Opin Genet Dev. 2007; 17(1):66-70.

9. Liu G, et al. High metastatic potential in mice inheriting a targeted p53 missense mutation. Proc Natl Acad Sci U S A. 2000;97(8):4174-4179.

10. Terzian T, et al. The inherent instability of mutant $\mathrm{p} 53$ is alleviated by $\mathrm{Mdm} 2$ or $\mathrm{p} 16 \mathrm{INK} 4 \mathrm{a}$ loss. Genes Dev. 2008;22(10):1337-1344.

11. Lowe SW, Cepero E, Evan G. Intrinsic tumour suppression. Nature. 2004;432(7015):307-315.

12. Xue W, et al. Senescence and tumour clearance is triggered by $\mathrm{p} 53$ restoration in murine liver carcinomas. Nature. 2007;445(7128):656-660.

13. Ventura A, et al. Restoration of p53 function leads to tumour regression in vivo. Nature. 2007; 445(7128):661-665.

14. Martins CP, Brown-Swigart L, Evan GI. Modeling the therapeutic efficacy of p53 restoration in tumors. Cell. 2006;127(7):1323-1334.

15. Montes de Oca Luna R, Wagner DS, Lozano G. Rescue of early embryonic lethality in $\mathrm{mdm} 2$ deficient mice by deletion of p53. Nature. 1995 ; 378(6553):203-206.
16. Jones SN, Roe AE, Donehower LA, Bradley A. Rescue of embryonic lethality in Mdm2-deficient mice by absence of p53. Nature. 1995;378(6553):206-208.

17. Hayashi S, McMahon AP. Efficient recombination in diverse tissues by a tamoxifen-inducible form of Cre: a tool for temporally regulated gene activation/inactivation in the mouse. Dev Biol. 2002; 244(2):305-318.

18. Milner J, Medcalf EA. Cotranslation of activated mutant p53 with wild type drives the wild-type p53 protein into the mutant conformation. Cell. 1991; 65(5):765-774

19. Cho Y, Gorina S, Jeffrey PD, Pavletich NP. Crystal structure of a p53 tumor suppressor-DNA complex: understanding tumorigenic mutations. Science. 1994;265(5170):346-355.

20. Prives C. How loops, beta sheets, and alpha helices help us to understand p53. Cell. 1994;78(4):543-546.

21. Sun Y, Dong Z, Nakamura K, Colburn NH. Dosagedependent dominance over wild-type 53 of a mutant p53 isolated from nasopharyngeal carcinoma. FASEB J. 1993;7(10):944-950.

22. Park DJ, et al. Transactivational and DNA binding abilities of endogenous p53 in p53 mutant cell lines. Oncogene. 1994;9(7):1899-1906.

23. Williams AC, Miller JC, Collard TJ, Bracey TS, Cosulich S, Paraskeva C. Mutant p53 is not fully dominant over endogenous wild type p53 in a colorectal adenoma cell line as demonstrated by induction of MDM2 protein and retention of a p53 dependent $\mathrm{G} 1$ arrest after gamma irradiation. Oncogene. 1995;11(1):141-149.

24. Davis P, Bazar K, Huper G, Lozano G, Marks J, Iglehart JD. Dominance of wild-type p53-mediated transcriptional activation in breast epithelial cells. Oncogene. 1996;13(6):1315-1322.

25. Liebermann DA, Hoffman B, Vesely D. p53 induced growth arrest versus apoptosis and its modulation by survival cytokines. Cell Cycle. 2007;6(2):166-170.

26. Das S, Boswell SA, Aaronson SA, Lee SW. P53 promoter selection: choosing between life and death. Cell Cycle. 2008;7(2):154-157.

27. Nakano K, Vousden KH. PUMA, a novel proapoptotic gene, is induced by p53. Mol Cell. 2001; 7(3):683-694.

28. Kaeser MD, Iggo RD. Chromatin immunoprecipitation analysis fails to support the latency model for regulation of p53 DNA binding activity in vivo. Proc Natl Acad Sci U S A. 2002; 99(1):95-100

29. Weinberg RL, Veprintsev DB, Bycroft M, Fersht AR. Comparative binding of p53 to its promoter and DNA recognition elements. J Mol Biol. 2005;348(3):589-596.

30. Roth JA. Adenovirus p53 gene therapy. Expert Opin Biol Ther. 2006;6(1):55-61.

31. Bykov VJ, et al. Restoration of the tumor suppressor function to mutant p53 by a low-molecularweight compound. Nat Med. 2002;8(3):282-288.

32. Gottesman MM. Cancer gene therapy: an awkward adolescence. Cancer Gene Ther. 2003;10(7):501-508.

33. McNeish IA, Bell SJ, Lemoine NR. Gene therapy progress and prospects: cancer gene therapy using tumour suppressor genes. Gene Ther. 2004; 11(6):497-503.

34. Schuler M, et al. Adenovirus-mediated wild-type p53 gene transfer in patients receiving chemotherapy for advanced non-small-cell lung cancer: results of a multicenter phase II study. J Clin Oncol. 2001;19(6):1750-1758.

35. Schuler M, et al. A phase I study of adenovirusmediated wild-type p53 gene transfer in patients with advanced non-small cell lung cancer. Hum Gene Ther. 1998;9(14):2075-2082.

36. Zeimet AG, Marth C. Why did p53 gene therapy fail in ovarian cancer? Lancet Oncol. 2003; 4(7):415-422.

37. Evans SC, Viswanathan M, Grier JD, Narayana M, El-Naggar AK, Lozano G. An alternatively spliced HDM2 product increases $\mathrm{p} 53$ activity by inhibiting HDM2. Oncogene. 2001;20(30):4041-4049.

38. Dimri GP, et al. A biomarker that identifies senescent human cells in culture and in aging skin in vivo. Proc Natl Acad Sci U S A. 1995;92(20):9363-9367.

39. Terzian T, Wang Y, Van Pelt CS, Box NF, Travis EL, Lozano G. Haploinsufficiency of Mdm2 and Mdm4 in tumorigenesis and development. Mol Cell Biol. 2007;27(15):5479-5485.

40. Barboza JA, Iwakuma T, Terzian T, El-Naggar AK, Lozano G. Mdm 2 and Mdm4 loss regulates distinct p53 activities. Mol Cancer Res. 2008;6(6):947-954.

41. Jackson JG, Pereira-Smith OM. Primary and compensatory roles for RB family members at cell cycle gene promoters that are deacetylated and downregulated in doxorubicin-induced senescence of breast cancer cells. Mol Cell Biol. 2006;26(7):2501-2510. 